\title{
The assessment of students' professional communicative competence: new challenges and possible solutions
}

\author{
Elena Genrikhovna Tareva - Boris Vladimirovich Tarev
}

DOI: 10.18355/XL.2018.11.02.59

\begin{abstract}
At present, due to significant attention to communicative competencies of University graduates, the assessment of an adequate level of their foreign language proficiency becomes one of the priority tasks of University education. The classical forms of assessment activities are not able to satisfy the need to identify the degree of communicative competence development. The solution of the problem of optimization of forms and methods of assessment is being conducted today in different directions by Russian and foreign researchers of second language teaching methods.

The article focuses on the conditions of carrying out of communicative competence assessment that ensure the improvement of the quality of the assessment at Universities. The authors propose some practical solutions for improvement of assessment procedures among University students.

Key words: communicative competence, assessment of foreign language communicative competence, self, peer, and teacher assessment
\end{abstract}

\section{Introduction}

At the present time, which is characterized by the development of the competence paradigm of higher professional education, the question of improvement of quality assessment system applied in the process of foreign language students' education is becoming more and more urgent. Assessment, which traditionally involves a combination of actions and operations aimed at comparison of an object with a standard, needs to be rethought today. This rethinking should be based on the latest reference benchmarks specific for contemporary Universities. These benchmarks are related to a modern set of goals (in other words standards) of training, which are interpreted nowadays in terms of competence parameters. Consequently, the system of second language assessment should be reoriented to prove the fact of correspondence / non-correspondence of the students' communicative competence to the social requirements for the foreign language training of professionals in a certain sphere of activity.

For University students, the strategic goal of learning a foreign language is the development of professional and communicative competence that ensures the individual's readiness to participate in professionally significant intercultural communication with colleagues from different linguistic and cultural communities. This competence includes a set of more specific competencies (sub-competencies), which, in turn, consist of "elementary" units - knowledge, skills, abilities, qualities, traits, etc. Orientation at certain goals predetermines the need to change the content of almost all the components of the methodological system, including the system of assessment. The existing forms of assessment prove to be ineffective since they are aimed at identifying only formal and explicit indicators of foreign language proficiency. Individual competencies being regarded as implicit changes, cannot be strictly algorithmized and formalized while monitoring and evaluating. The discrepancy between the expected result, which is interpreted in competence parameters, and assessment procedures that still exist in the long-established traditional and already outdated spectrum of types, forms, and practices, has been repeatedly mentioned in the scientific literature (Tareva, 2015). 


\section{The aim of the Study}

In connection with what has been said, it becomes necessary to identify the conditions that can be used as the basis for creating innovative forms of control aimed at determining the level of the formation of the professional and communicative competences of University students.

The aim of the study is to examine the theoretical basis of assessment of competences specific for students' foreign language proficiency.

The research questions are: What are the didactic parameters of a competency oriented assessment? What are the main difficulties of such assessment? What are the conditions for effective assessment of students' communicative competence? What are the technologies for conducting competence-based assessment?

\section{Data \& Analysis}

The first and significant condition in the context of teaching a foreign language is taking into account during the organization and conduct of assessment procedures of the features and characteristics of professional activities of future specialists (Tarev, 2009). This means that assessment and evaluation in all their forms and techniques should be aimed at revealing the degree of development of those student's qualities, properties, characteristics, knowledge, and skills that are necessary for professional, communicative activity in a specific sphere of employment. This means that the assessment of the professional and communicative competence of future economists should be different from the assessment of similar competencies among, for example, future engineers, mathematicians, historians, etc. The parameters of assessment and evaluation will be determined by the core spheres of the specialist's professional activity. Only such approach can verify the quality of professional training.

It is necessary to indicate one more condition for the effectiveness of assessment of the development of professional and communicative competence. It is associated with the need to take into account the level of vocational education. This means that the assessment and evaluation should be aimed at identifying the specific characteristics inherent in the bachelor / specialist / master of the relevant branch of knowledge. Each of these students has special requirements that embody themselves in the parameters of professionally significant competencies. Therefore, the approaches to the organization of assessment procedures and content for different University graduates should vary and be modified.

The other condition is related to the need for the assessment and evaluation to be focused not only on the explicitly but also on the implicitly expressed features and qualities of a professional. This means that the assessment, in addition to traditional objects, must identify those personality parameters that are hidden for direct observation and which only indirectly manifest themselves in the professionally oriented communicative activity of an individual. (These objects of assessment were almost completely and totally ignored as immeasurable). Among such parameters, in particular, we can mention such personality traits as entrepreneurship, the speed of decision making, energy, self-discipline, etc.

This condition necessitates the development of a special criteria scale of assessment, the creation of which is objectively difficult due to the complexity of identifying and describing implicit parameters of professionally significant competencies. The solution of this problem can be regarded as another condition that ensures the effectiveness of assessment of the development of students' professional and communicative competence. We know that at the present time there are several

XLinguae, Volume 11, Issue 2, April 2018, ISSN 1337-8384, eISSN 2453-711X 
attempts to solve this problem (Lieu Tran et al., 2017; Santos et al., 2014; Adsanatham, 2012; Birova et al., 2016). Despite the efforts of the authors, the issue of developing criteria, criteria scales aimed at identifying competencies, has not been finally solved and requires serious attention.

In connection to what has been said above, there is one more condition, concerning the need to diversify (in comparison with the existing traditional set) types and forms of assessment that acquires special significance. It is necessary to abandon adherence to purely traditional forms of assessment (tests, quizzes, surveys, etc.), they must be supplemented with innovative forms that are aimed specifically at identifying the level of the formation of the professional and communicative competence of the future specialist. Such forms can be, for example, referring to the solution (by means of a foreign language as a means of communication) of problematic professional tasks, holding scientific conferences on professional issues, etc.

In addition to what has been said, it is also necessary to apply new types of assessment. Beside cross-sectional measurement (one-time testing, for example), it is advisable to provide longitudinal measurements of professional and communicative competence. Only in this way we can check the sustainability of the acquired material, objectively determine the permanence and stability of the actualization of the professionally significant qualities.

The other condition necessary for assessment procedures is specified by the problem-based content of assignments. As a consequence, it is necessary to revalue the ratio of productive and reproductive types of assessment tasks in favor of the former. This particular condition seems to provide the solution to the problem of optimization and modernization of assessment in connection with the need to develop students' professional and communicative competence. Competence in its essence is associated with a real professional context, which is often unforeseen, being sophisticated in nature. Therefore, it is necessary that in the process of assessment students should exhibit their ability to solve new professional tasks using a foreign language. In the course of such activities, students should be able to express their own opinion, reflecting their individual professional worldview and demonstrating individual professional and communicative profiles. It should be noted that, traditionally, this parameter of training is almost completely ignored even in the course of final testing at University.

With a problem-intensive approach to the assessment of competences, many difficulties arise. According to the authors (Alias et al. 2015), one of the most significant difficulties is that students and teachers have different perceptions, leading to differing viewpoints in assessments. In other words, there is no correlation between student grades (self and peer) and teacher assessment.

Moreover, the important factor in connection with the competence approach to higher vocational education is the condition connected with taking into account the individual traits of students. Each student manifests his/her professionally important feature and personal qualities in different ways, forming an individually distinctive profile of the professional activity, an individual style of professional and communicative activity. In this regard, it is necessary to provide the variability of testing assignments, through variation of tasks wording, scope, and quality of such assignments.

Taking into consideration the active position of students is another important condition for the effectiveness of assessment. The students should be acquainted with the evaluation criteria, with the requirements for the procedure and the result of the assessment (Brantmeier et al., 2012) Students should know the objects subjected to assessment, they should be aware of the requirements to the quality of their activities. The assessment should be recognized as ineffective if a student is not able to prepare himself for testing independently, evaluate himself 
before, during and after it, and outline ways to improve the achieved results. Thus, assessment is regarded as a procedure that gives the opportunity for students to prove their professional and communicative autonomy, their responsibility in the process of the implementation of foreign-language communicative activities.

Competence-based assessment requires Self, Peer and Teacher Assessments (Roffé Gómez, 2014). In order to obtain a holistic view of students' contribution, self-assessment and peer-assessment are often used in addition to teacher assessment to arrive at the overall course grade of a student in problem-based learning.

\section{Results and Discussion: Business School}

There are some innovative practices of self, peer, and teacher assessments of competencies that can be applied to second language students. Some authors propose a number of practices that have already proved their efficiency:

a) an oral semi-structured interview, collaborative work rubrics, and communicative competence rubrics (Roffé Gómez, 2014);

b) oral presentations in a second language, where the testing process is carried out in two ways: peer and self-assessment (Gil-Salom et al., 2016);

c) simultaneous introduction of self-report, peer-report, and teacher's ratings (Alias et al., 2015);

d) implementation of an integrated reading-to-write task (Kim et al.,

During 2014-15 and 2015-16 academic years we conducted a validity check of communicative competence among students ( 82 students) of the Faculty of International Affairs and World Economy at National Research University Higher School of Economics (Moscow, Russia).

One-on-One Interviews (OOI) as a common qualitative research tool are in-depth interviews conducted one-on-one between an individual respondent and a professional qualitative researcher. OOI is similar to focus groups, but there are a few key differences worth noting. OOI tend to be more structured, shorter and allow each respondent to share their personal experiences and opinions in greater depth and detail than can generally be achieved in a focus group setting.

- Professionally Oriented Debate (POD) as an educational tool that motivates students to express their opposite opinions with the goal of contradicting each other's arguments. An opportunity for decision may be given after opposing views are presented in alternating statements. Through reinforcing already taught materials by creating a fast argument-based response environment debating is found to improve learning competencies.

Task-Based Language Assessment (TBLA) is «the process of evaluating, in relation to a set of explicitly stated criteria, the quality of the communicative performances elicited from learners as part of goal-directed, meaningfocused language use requiring the integration of skills and knowledge» (Brindley, 1993, p. 74). Such assessments are used to determine the extent to which second language users can demonstrate the kinds of language abilities that will be called upon in particular discourse domains, and they can lead to decisions about program admissions and/or placement into opportunities for further language study.

Business Games (BG) is an assessment tool which evaluates students while engaging them in a simulated experience of the real-world and immersing them in an authentic management situation. Such approach to educational 
activity motivates information search, analysis, interpretation, problem-solving, and decision-making.

A team of experts (3 native speakers, 8 highly qualified teachers of English), recorded on video, analyzed the students competences assessment procedures in accordance with the following criteria: precision of the objects of assessment (1), professional validity of assessment (2), integrated content of assessment procedures (3), consideration of manifestation of personal characteristics of students in the process of assessment (4), 'embeddability' of assessment in educational technologies, transparency of assessment for the learners (5), transparency of procedures for all the participants of the educational process and consumers of educational products (6), implementation of user-friendly technique of selfassessment (7). At the same time the procedures were evaluated by the students using the same criteria. Aggregated data (as a percentage) are shown in the figure below (fig. 1).

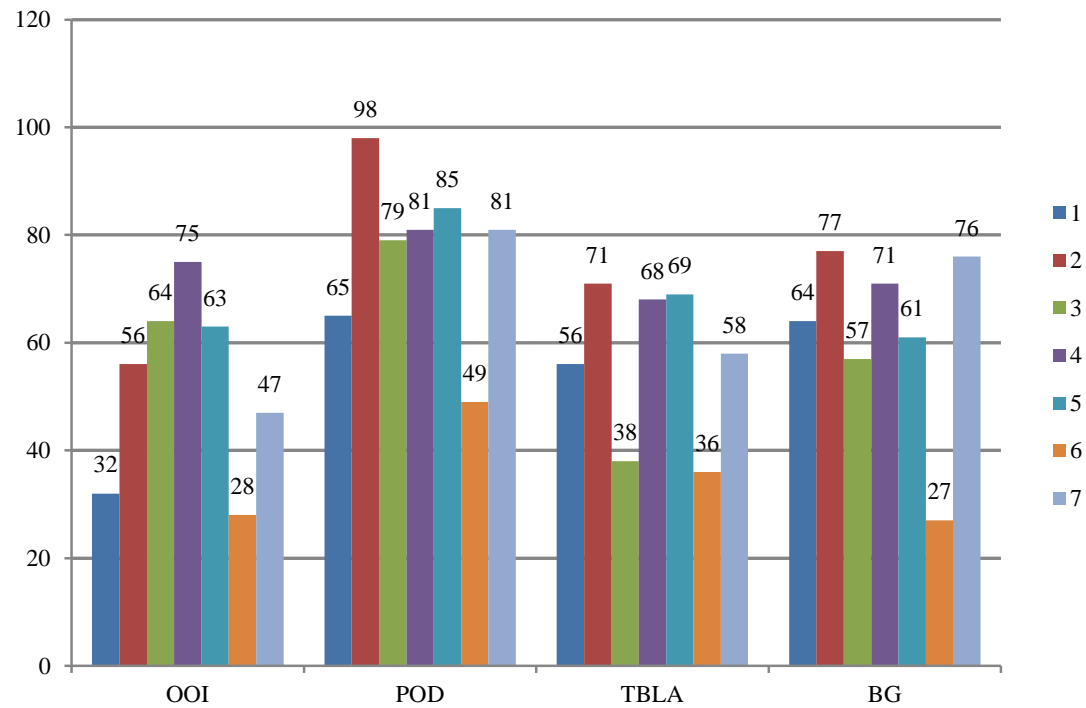

Figure 1.The degree of compliance of competence assessment procedures with the set parameters

The analysis of the data received allows us to conclude that the most effective way to assess the level of development of communicative competence in the process of second language teaching and learning is Professionally Oriented Debate.

\section{Results and Discussion: Teacher Training School}

Proficiency assessment of pre-service second language teachers in Russian Universities has long been determined by two main parameters: a) assessment of knowledge and skills in the sphere of a foreign language; b) assessment of knowledge of graduates in the field of pedagogy and methods of second language teaching. Both assessment objectives were achieved through testing, which were weakly related to each other and almost completely unrelated to actual teaching practice.

The analysis of the content and procedure of the traditional final exam at Teacher Training School (from 2010 to 2014) showed that the assessment was not focused on evaluation of graduates' competencies. It did not correlate with the 
professional context of pre-service teacher's - a graduate of the bachelor's degree activity. The control was not based on objective special criteria scale of assessment. Examiners were mainly affected by their own subjective opinions about learners as students, not future professionals. The examination commission did not include representatives of the professional environment - real second language teachers, who are well aware of the conditions of the modern school and the requirements imposed on teachers. The content of testing was always the same and monotonous and included: a) foreign language text analysis and retelling, b) the answer to the question about one of the phenomena of foreign language system, and c) the answer to the question from the field of pedagogy, psychology, and methods of teaching foreign languages. The innovative technologies for the assessment of the level of proficiency of Teacher Training School graduates were not in demand. Besides, the students were not included in the process of assessment. As a consequence, only teacher's assessment was implemented, the possibilities for self-assessment and peerassessment were not provided.

In addition, in the assessment process, feedback is not established, although its role is very important in the training of future professionals. As determined by scientists, students need to use those settings, which are potentially feedback-rich. For example, they include «the teacher's working through a test or assignment when it was returned to the students after corrections, student presentations of their projects, group-work, and discussions among the teacher and students» (Havnes et al., 2012, p. 26).

Thus, the traditional control is not aimed at setting problems to be solved; it does not reveal the characteristics of the student, the individual style of his communicative behavior and making pedagogical decisions. The main thing is that traditional control does not determine the graduate's readiness for full-fledged professional work, for working in a modern school, for preparing schoolchildren for the use of a foreign language in their life.

Taking into account the existing conditions, which have a negative impact on the identification of the true abilities of pre-service second language teachers, scientists began to search for ways to improve assessment technologies. Studies are conducted in different directions. The ePortfolio approach is applied to faculty development and performance evaluation at vocational education institute (Hoekstra et al., 2015); Academic Professional Development Effectiveness Framework is designed as an evaluation tool to facilitate the systematic collection and analysis of data related to the intended outcomes of the teacher development programmes (Chalmers et al., 2015)

Within three years (2015-2017) we conducted an experiment to introduce a new form of organization of the final exam for the readiness of pre-service second language teachers for professional activities. The exam included two main parts, each of which was founded on a task-based approach and was maximally oriented to the pedagogical context of activities, taking into account the individual characteristics of students, manifested in the conditions of decision-making in non-standard, uncertain circumstances of professional activity.

The first part of the exam was conducted in the form of students' presentation of the project, aimed at the design of a foreign language lesson plan at a certain level of a comprehensive school. Prior to the exam, the students were given the assignments to design plans for certain school forms, textbook units, and other conditions of professional activity, which they had to take into account in the process of preparation. Initially, a team (3-4 people) discussion of the concept of the textbook, the idea, and the main goal of the team was carried out. Thus, the strategies of peerassessment and self-assessment were actualized. This was followed by the individual

XLinguae, Volume 11, Issue 2, April 2018, ISSN 1337-8384, eISSN 2453-711X 
work of each student on drawing up of a foreign language lesson plan with its scientific verification. In the text of the verification, the student explained the decisions he made when drawing up the lesson plan, demonstrating in complex the knowledge of pedagogy, psychology, methods of teaching second languages, conflictology, sociology, educational law, and other spheres. The decisions made were justified by a) the goals and objectives of the lesson, b) the teaching principles, c) the structure of the lesson, d) the system of communicative, cognitive tasks, e) new educational technologies and foreign language teaching tools.

In the course of the presentation of their project, pre-service second language teachers disclose the logic of the lesson, prove the effectiveness of solving the tasks of the lesson and justify their own point of view on the use of educational technologies. Further, a discussion with the examiners (experienced teachers of a second language) is carried out. They ask the student questions about the real practice of teaching at the school. Following the results of the presentation and discussion, a decision is made about the student's professional qualifications in accordance with the requirements that are set for the teacher of a modern school.

The second part of the exam is aimed at assessment of the level of development of professionally oriented communicative competence. Pre-service second language teachers should demonstrate the ability to solve communicative tasks in the sphere of professional communication (level C1) with the application of knowledge and skills in the theoretical and practical aspects of a second language and foreign culture. Students should demonstrate their readiness to conduct quasi«dialogue of cultures» in specially simulated conditions in accordance with the norms of intercultural communication using strategies and practices adequate to the professional and communicative situation of interaction with foreign colleagues. Here is an example of a problem assignment for pre-service French language teachers.

Vous accompagnez un groupe d'écoliers et vous voulez visiter la Cité de l'espace la semaine prochaine. Pour faire améliorer le français du groupe, vous envisagez l'opportunité de faire la visite avec des audioguides. Dans votre groupe il y a des enfants d'âge different, des personnes à mobilité réduite.

Moreover, the students should show readiness to analyze authentic audio, video, as well as textual material and make a decision how to apply it in various conditions of teaching a second language (school form, language proficiency, didactic task, educational conditions). The exam organized in this way showed that students demonstrate all the components of the professional competence of a second language teacher: gnostic competence, design competence, technological competence, communicative competence, corrective competence, reflexive competence (Yazykova, 2015). Fig. 2 shows the results of the competency assessment (max 100 points) during three years when the new model of the final exam was applied. 


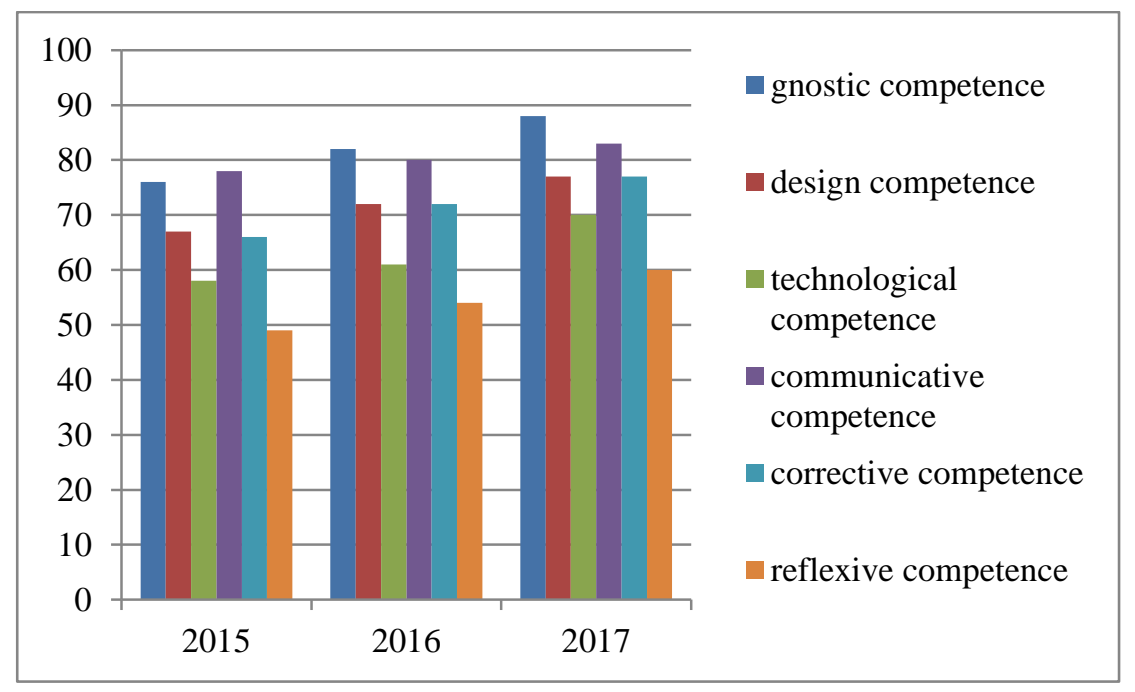

Figure 2. The results of the assessment of professionally significant competencies during the final exam among pre-service French language teachers

\section{Conclusion}

So, this article presents a new approach to the modernization of the assessment system aimed at identification of the specific parameters of the student's personality - competencies that ensure his participation in professionally meaningful communication with a representative of another linguistic and cultural community. It is well known that it is the assessment system that allows determining the quality of specialists' training. Hence, the degree of effectiveness of graduates' readiness for professional and communicative activities in a foreign language depends on this system and its ability to identify objective indicators. This article presents and justifies a number of conditions that ensure the effectiveness of assessment procedures.

The system of assessment requires undergoing significant revision, which requires a number of conditions. The authors found that these conditions include: consideration of the parameters of the student's professional activity, level of educational system, focus on identifying not only explicit (traditional), but also implicit (innovative) assessment objects; development of a transparent scale of assessment criteria that is understandable not only to the teacher, but also to the students with the variety of forms and methods of assessment, the involvement of students in the process (self-assessment and peer assessment); application of the problem-based approach to organization and carrying out of assessment. Experimental organization of assessment in different educational environments (business school and teacher training school) has shown the effectiveness of new assessment technologies and practices that take into account the stated above conditions.

\section{Bibliographic references}

ADSANATHAM, CH. 2012. Integrating assessment and instruction: Using studentgenerated grading criteria to evaluate multimodal digital projects.Computers and Composition, vol. 29, Issue 2, pp. 152-174. DOI: https://doi.org/10.1016/j.compcom.2012.04.002 
ALIAS, M. - MASEK, A. - MD SALLEH, H.H. 2015.Self, peer and teacher assessment in problem based learning: are they in agreements? Procedia - Social and Behavioral Sciences, vol. 204, pp. 309-317. DOI: https://doi.org/10.1016/j.sbspro.2015.08.157

BIROVA, J. - BARANCOVA, M. - SIMKOVA, Z. 2016. A note on terminology: bilingualism, plurilingualism and plurilingual intercultural competence or are we all plurilingual? XLinguae, pp. 114-127. DOI: 10.18355/XL.2016.09.02.114-127

BRANTMEIER,C. -VANDERPLANK,R. - STRUBE, M. 2012. What about me?: Individual self-assessment by skill and level of language instruction. System, vol. 40, Issue 1, pp. 144-160. DOI: https://doi.org/10.1016/j.system.2012.01.003

BRINDLEY, G. 1993. Task-centred assessment in language learning: The promise and the challenge. In Bird N., Falvey P., Tsui A., Allison D., McNeill A. (Eds.). Language and learning: Papers presented at the Annual International Language in Education Conference, Hong Kong: Hong Kong Education Department, 1993, pp. 73-94.

CHALMERS, D. - GARDINER, D. 2015. An evaluation framework for identifying the effectiveness and impact of academic teacher development programmes. Studies in Educational Evaluation, vol. 46, pp. 81-91. DOI: https://doi.org/10.1016/j.stueduc.2015.02.002

GIL-SALOM, D. - BENLLOCH-DUALDE, J.-V. 2016. Student assessment of oral presentations in German as a foreign language. Procedia - Social and Behavioral Sciences, vol. 228, pp. 656-661. DOI: https://doi.org/10.1016/j.sbspro.2016.07.100 HAVNES, A. - SMITH, K. - DYSTHE, O. - LUDVIGSEN K. 2012. Formative assessment and feedback: Making learning visible. Studies in Educational Evaluation, vol. 38, Issue 1, pp. 21-27. DOI: http://dx.doi.org/10.1016/j.stueduc.2012.04.001

HOEKSTRA, A. - CROCKER, J.R. 2015. Design, implementation, and evaluation of an ePortfolio approach to support faculty development in vocational education. Studies in Educational Evaluation, vol. 46, pp. 61-73. DOI: https://doi.org/10.1016/j.stueduc.2015.03.007

KIM, AH-Y. - KIM, H.J. 2017. The effectiveness of instructor feedback for learningoriented language assessment: Using an integrated reading-to-write task for English for academic purposes. Assessing Writing, vol. 32, pp. 57-71. DOI: https://doi.org/10.1016/j.asw.2016.12.001

LIEU TRAN, T.B. -HO,T.N.- MACKENZIES.V. - LONG, K.L. 2017.Developing assessment criteria of a lesson for creativity to promote teaching for creativity.Thinking skills and creativity, vol. 25, pp. 10-26. DOI: https://doi.org/10.1016/j.tsc.2017.05.006

ROFFE GOMEZ, A. 2014. Foreign language testing through competence assessment rubrics and oral interviews in the european higher education area.Procedia - Social and Behavioral Sciences, vol. 141, pp. 524-532. DOI: https://doi.org/10.1016/j.sbspro.2014.05.091

SANTOS, L. - PINTO J. 2014. The development of self-regulation through assessment criteria. Procedia - Social and Behavioral Sciences, vol. 112, pp. 907-915. DOI: https://doi.org/10.1016/j.sbspro.2014.01.1248

TAREV, B.V. 2009. Conditions of effectiveness of monitoring of professional communicative competence among non-linguistic students, The Herald of Buryat State University, № 15, pp. 244-246. ISSN: 1994-0866

TAREVA, E.G. 2015. Innovation potential of lingvodidactic traditions: competenceoriented assessment, Foreign languages at school, № 6, pp. 3-8. ISSN: 0130-6073

YAZYKOVA, N.V. - MAKEEVA, S.N. 2015. The development of methodological competence of foreign language teacher at University. Moscow: Tezaurus, $288 \mathrm{p}$. ISBN: 978-5-98421-296-0. 
Words: 4205

Characters: 29960 (16,64 standard pages)

Elena Genrikhovna Tareva, $\mathrm{PhD}$ in Pedagogy, Full Professor

French Language Department

Moscow City University

$2^{\text {nd }}$ Selskokhoziastvenny Proezd 4

129226 Moscow

Russian Federation

TarevaEG@mgpu.ru

Boris Vladimirovich Tarev $\mathrm{PhD}$ in Linguistics, Associate Professor

Foreign Languages Department

National Research University Higher School of Economics

Myasnitskaya 20

110100 Moscow,

Russian Federation

btarev@hse.ru 